\title{
MAJELIS DZIKIR:
}

\section{Antara Sadar Spiritual dan Praktek Budaya Massa}

\author{
Musthofa Al Makky \\ Program Pascasarjana (PBA) UIN Maulana Malik Ibrahim Malang. Jalan \\ Gajayana No.50 Malang.Telp.085649714433, email: ikam_86@yahoo.com
}

\begin{abstract}
Abstraks
Yogyakarta merupakan salah satu daerah Istimewa di Indonesia yang mempunyai budaya bernafaskan Islam. Sejarah Kerajaan Mataram sebagai Kerajaan Islam, melalui pejanjian Giyanti (1755) telah melahirkan Keraton Yogyakarta sebagai bagian sejarah Islam di Mataram. Pengaruh Islam dalam masyarakat Yogyakarta dapat dijelaskan melalui teori budaya. Budaya jika ditinjau dari struktur dan tingkatannya dapat dijelaskan bahwa Islam sebagai subculture yang tidak bertentangan dengan culture Jawa sebagai kebudayaan induk, menjadikan Islam dapat diterima masyarakat Jogyakarta sebagai agama yang benar. Nilai-nilai Islam telah menyatu dengan nilai-nilai kehidupan masyarakat Yogyakarta, sehingga banyak cara berpikir dan tindakan yang dilakukan cenderung bernafaskan Islam. Hal ini dapat ditunjukkan melalui seni, sastra, kegiatan sosial dan prinsip hidup yang diyakini masyarakat Jogyakarta.
\end{abstract}

\begin{abstract}
:
Man was created with the provision of spiritual awareness of the existence of God. When in the course of his life to find a variety of problems, which he first headed the Lord. From every human being must feel that awareness. If then it is collective awareness activities conducted in order to meet the spiritual needs that can be implemented together. That is a God given institution called the Assembly of dzikir. If then the activity was done with a lot of people, over time some of them do not know the exact substance and virtues of the assembly itself, but just following everyone else alone. Moreover, many activities that involve mass was boarded by-worldly orientation of material interests, economic and political. Then the activity will become a kind of wetland that can be exploited in the interests of a handful of people.
\end{abstract}

Key words: majelis dzikir, spiritual awareness, mass culture

\section{Pendahuluan}

Esensi agama Islam adalah moral, yaitu moral antara seorang hamba dengan Tuhannya, antara seorang dengan dirinya sendiri, antara dia dengan orang lain, termasuk anggota masyarakat dengan lingkungannya. Moral seorang dengan 
dirinya melahirkan tindakan positif bagi diri, seperti menjaga kesehatan jiwa dan raga, menjaga fitrah dan memenuhi kebutuhan-kebutuhan ruh dan jasmani (Jumantoro, dkk., 2005:xxi), dengan demikian, krisis moral tidak akan terjadi padanya. Selanjutnya moral yang terjalin pada hubungan antara seorang dengan orang lain, menyebabkan keharmonisan, kedamaian dan keselarasan dalam hidup yang dapat mencegah, mengobati berbagai krisis (spiritual, moral, dan budaya).

Majelis dzikir yang akhir-akhir ini marak diselenggarakan di berbagai daerah merupakan salah satu bentuk pengobatan krisis spiritual yang dialami oleh seseorang. Majelis doa bersama ini sebuah rekonstruksi dari kegiatan serupa yang dikenal dan masyhur di Indonesia pada satu dasawarsa terakhir dengan sebutan istighotsah. Namun beberapa tahun terakhir bermetamorfosis menjadi sebuah gelaran yang diikuti oleh ribuan masyarakat muslim Indonesia dengan istilah majelis dzikir. Kegiatan ini bukan lain adalah satu bentuk macam dari aktifitas tasawuf seorang yang kemudian dilakukan bersama dalam satu tempat majelis.

Kehidupan beragama mayarakat kelas menengah perkotaan tidak dapat dipandang sebagai sesuatu yang benar-benar independen, karena hal ini pada kenyataannya selalu terkait dengan struktur ruang waktu tertentu yang turut membentuknya. Rutinitas harian yang terjadwal rapi dan iklim kompetisi yang tinggi membuat masyarakat perkotaan hidup dalam bayang-bayang tekanan. Orientasi hidup yang selalu tertuju pada persoalan eksternal (prestasi kerja, aktualisasi diri, karier, dan sebagainya) juga telah memaksa masyarakat perkotaan tampil berdasarkan mimpi bersama, yang memicu munculnya penurunan kualitas penghayatan terhadap kebutuhan diri pribadi.

Fenomena kembali menyingsingnya fajar spiritualitas di tengah ingar-bingar kehidupan perkotaan sebenarnya telah diprediksi oleh John Naisbit dalam Megatrends 2000 hampir dua dekade yang lalu (Afif, 2007). Kemajuan di bidang ekonomi, ilmu pengetahuan, dan teknologi, kehidupan manusia modern dirasakan lebih mudah, lebih sejahtera, tapi pada saat yang sama, kemajuan peradaban dewasa ini juga membuat manusia tidak bahagia, kehilangan makna hidup, dan merasa teralienasi. Penyebab teralienasinya manusia dari kehidupannya bersumber pada terputusnya hubungan manusia modern dengan 
nilai-nilai spiritualnya.

Fenomena spiritualitas yang terjadi akhir-akhir ini barangkali telah menggugurkan hipotesis Emile Durkheim yang menyatakan bahwa sikap dan perilaku spiritual mustahil muncul pada masyarakat modern. Karena menurut Durkheim masyarakat modern sangat individualis, memiliki pembagian kerja yang tinggi, perbedaan kepentingan dan keyakinan serta memiliki solidaritas yang rendah. Rumusan yang mengatakan bahwa spiritualitas berbanding lurus dengan modernitas suatu masyarakat agaknya tidak selalu benar. Karena pada mayarakat modern seperti saat ini spiritualitas sudah menjadi trend tersendiri (Taufiq, 2005).

Manusia modern membutuhkan pegangan, petunjuk jalan, atau semacam obat penenang, agar mereka tidak terjebak dalam kegersangan hidup di rimba perkotaan. Mereka juga butuh figur, butuh pembimbing, yang sanggup memandu, meniti, dan melempengkan jalan menuju firdaus, sebab kehampaan batin yang dirasakan manusia modern adalah hilangnya vitalitas dan sering kali berujung pada pesimisme, semacam ketidakberdayaan menemukan sumber kebahagiaan secara mandiri.

Seorang yang sadar akan krisis spiritual dalam dirinya kemudian melaksanakan sebuah ajaran agama. Ajaran agama itu tentu berkaitan erat dengan tasawuf yang dapat mendorong manusia untuk memelihara dirinya dari menelantarkan kebutuhan-kebutuhan spiritualnya. Sebab menelantarkan kebutuhan spiritualitas sangat bertentangan dengan yang dikehendaki Allah SWT. Untuk mengentaskan kekeringan spiritualitas itu berdzikir perlu dilakukan. Manifestasi agama tersebut diekspresikan dalam kaidah dan bentuk-bentuk yang beragam (Yudha, 2004:82). Memang harus diakui bahwa prosedur untuk memberdayakan agama bagi pemecahan masalah praktis seorang, masih memerlukan artikulasi yang lebih lengkap dan rinci.

Satu sisi sadar akan spiritual itu tepat bila orang pelaku dzikir dalam majelis itu tahu akan manfaat dan subtansi lafadz-lafadz yang diucapkan. Dia tahu manfaat dan keutamaan bacaan-bacaan dzikir yang diikutinya dari seorang panutan atau imam dzikir. Namun bila mereka ikut dalam majelis dzikir hanya mengikuti arus masyarakat sekitar yang membawanya ke sana, maka bukan tidak 
mungkin aktifitas ibadah itu adalah budaya masyarakat (budaya massa) semata, yang sedang dipraktekkan oleh masyarakat dalam sebuah kurun waktu. Ibadah dzikir yang dipraktekkan oleh banyak orang yang kurang dipahami subtansinya akan melahirkan sebuah produk budaya dari masyarakat yang berawal dari tiruan (imitasi). Bukan lagi bersifat kesamaan pemenuhan kebutuhan rohani bagi masing-masing pelaku dzikir, serta diboncengi oleh kepentingan yang bukan sekedar obat kegersangan spiritual.

\section{Mass Culture}

Mengenai budaya massa, ini adalah istilah kita untuk mass culture. Istilah Inggris ini konon berasal dari bahasa Jerman Masse dan Kultur. Sebenarnya istilah "kebudayaan massa" sendiri merupakan istilah yang mengandung nada mengejek atau merendahkan. Istilah ini merupakan pasangan dari high culture, kebudayaan elite atau kebudayaan tinggi (Ibrahim, 2005:5).

Biasanya, istilah "kebudayaan tinggi" diacukan tidak hanya ke berbagai jenis produk simbolik yang menjadi pilihan kaum elit terpelajar dalam masyarakat Barat, tetapi juga ke segala sesuatu yang ada kaitannya dalam pikiran dan perasaan mereka yang memilih jenis kesenian dan produk simbolik tersebut. Sebaliknya, mass atau masse mengacu ke mayoritas masyarakat Eropa yang tak-terpelajar dan non-aristokratik, terutama sekali masyarakat yang sekarang ini biasa kita sebut sebagai kelas menengah bawah, kelas pekerja, dan kaum miskin. Dengan demikian, jika "kebudayaan tinggi" dikaitkan dengan mereka yang "berbudaya", yang elit dan terpelajar, maka istilah "kebudayaan massa" dianggap milik mayoritas masyarakat tak berbudaya dan tak-terpelajar (Ibrahim, 2005:5)

Dalam Sosiologi, menurut Blummer (Bungis, 2007:98), istilah massa mengandung pengertian kelompok manusia yang tak bisa dipilah-pilah, bahkan semacam kerumunan (crowd) yang bersifat sementara dan dapat dikatakan: segera mati. Dalam kelompok manusia yang seperti ini, identitas seseorang biasanya tenggelam. Masing-masing akan mudah sekali meniru tingkah laku orang-orang lain yang sekerumunan atau sekelompok. Puncak dari tingkah laku mereka akan dilalui, katakanlah maksudnya selesai, apabila secara fisik mereka sudah lelah dan tujuan bersamanya tercapai. 
Begitu pula halnya dengan kebudayaan. Kebudayaan massa lebih kurang menunjuk pada berbagai produk dan praktek-praktek kultural yang melibatkan sekumpulan besar orang tanpa organisasi sosial, adat, tradisi, struktur peran dan status, tidak memiliki kompetensi dalam menilai kualitas suatu produk budaya, dan juga berselera dangkal. Bagi mereka yang "terjerat" di dalamnya, produk-produk dari kebudayaan massa adalah komoditas yang semata-mata ditujukan untuk konsumsi, dan tanpa mereka sendiri memiliki kesanggupan untuk menolaknya meskipun umur produk-produk itu relatif sementara.

Bagaimana dapat mengenali produk-produk dan atau praktek-prakteknya? Untuk mengenalinya, menurut Kuntowijoyo dalam tulisannya "Budaya Elite dan Budaya Massa" dalam Ecstasy Gaya Hidup: Kebudayaan Pop dalam Masyarakat Komoditas Indonesia (2004), dapat dilihat dari ciri-ciri yang selalu menyertainya. Sebab kebudayaan massa adalah akibat dari massifikasi. Adapun massifikasi sendiri, terjadi bila orang kebanyakan memakai simbol lapisan atas melalui proses industrialisasi dan komersialisasi dalam sektor budaya, sekalipun industrialisasi dan komersialisasi tidak selalu berarti negatif bagi budaya.

Ciri pertama adalah objektivasi; artinya, pemilik hanya menjadi objek, yaitu penderita yang tidak mempunyai peran apa-apa dalam pembentukan simbol budaya. Ia hanya menerima produk budaya sebagai barang jadi yang tidak boleh berperan dalam bentuk apapun. Ciri kedua adalah alienasi; artinya pemilik budaya massa akan terasing dari dan dalam kenyataan hidup. Dengan demikian ia juga kehilangan dirinya sendiri dan larut dalam kenyataan yang ditawarkan produk budaya. Dan ciri ketiga (ciri terakhir) adalah pembodohan, yang terjadi karena waktu terbuang tanpa mendapatkan pengalaman baru yang dapat dipetik sebagai pelajaran hidup yang berguna jika ia mengalami hal serupa.

Senada dengan itu, Sapardi Djoko Damono dalam tulisannya "Kebudayaan Massa dalam Kebudayaan Indonesia: Sebuah Catatan Kecil” dalam Ecstasy Gaya Hidup: Kebudayaan Pop dalam Masyarakat Komoditas Indonesia (2004), mengatakan bahwa pada hakikatnya yang dirisaukan adalah kebudayaan massa ini yang sebagai akibat dari semakin berkembangnya komunikasi, memang tak dapat dihindari. Menurutnya, ada beberapa hal yang menyebabkan kerisauan itu: (1) 
kebudayaan massa diproduksi secara besar-besaran berdasarkan perhitungan dagang belaka, (2) kebudayaan massa itu merusak kebudayaan tinggi dengan cara meminjam atau mencuri atau memperalatnya, (3) kebudayaan massa menanamkan pengaruh yang sangat buruk terhadap khalayak, dan (4) penyebarluasan kebudayaan massa dianggap tidak hanya memerosotkan atau mengurangi nilai kebudayaan (tinggi) itu sendiri tapi juga menciptakan khalayak yang pasif yang sangat tanggap terhadap berbagai teknik godaan dan bujukan, sehingga membuat peluang bagi munculnya totalitarianisme.

Sedangkan pada budaya massa, sebagai kritik atas budaya tradisional, merujuk kepada proses pluralisme dan demokrasi yang kental, berusaha untuk menghilangkan kelas-kelas yang mendasarkan dirinya pada budaya modal, borjuasi dan elitisme, dengan mengedepankan kebersamaan dan egalitarianisme (Patters, 2010). Namun secara negatif, budaya massa juga banyak diartikan sebagai perilaku konsumerisme, kesenangan universal yang bersifat hanya seketika, mudah punah, dan memiliki makna yang dangkal dan tidak bersifat ganda, mengacu kepada pengertian produk budaya yang diciptakan semata-mata untuk pasar. Dengan kata lain dalam budaya massa, orientasi produk adalah trend atau model yang sedang diminati pasar.

Kesamaan atau keseragaman model dan etos adalah corak terpenting dalam kebudayaan massa. Dalam hal ini perilaku yang muncul adalah proses imitasi dan peniruan, dimana proses ini adalah hasil dari kecenderungan manusia untuk melakukan imitasi atas nilai dan bentuk-bentuk yang dipercaya atau dirasakan mempunyai kecocokan. Namun, pada konteks budaya massa, peniruan yang mengarah pada keseragaman ini dibentuk secara terperinci dan sistematis oleh sebuah otoritas politik ekonomi, yang diimplementasikan oleh kekuatan komunikasi massa dengan institusi medianya serta kepentingan ekonomis dan ideologis orang-orang yang berada didalamnya.

\section{Kajian Kritis}

Majelis dzikir berasal dari gabungan kata majelis yang berarti lembaga, dan dzikir yang berarti mengingat, memperhatikan, mengenang, mengambil pelajaran, mengenal, atau mengerti, ingatan, sehingga bisa diartikan bahwa 
majelis ini adalah sebuah organisasi yang terbentuk dengan kesamaan tujuam dari manusia yang ada di dalamnya, untuk mengingatkan pengetahuan tentang agama Islam, jugaa untuk memperdalam ketaatan pada segalaa perintah Allah SWT (Ahira, 2007). Majelis dzikir persertanya biasanya datang dari kelompok-kelompok yang rutin mengadakan kajian tentang agama.

Secara terminologis, dzikir menurut Spencer Trimingham (Jumantoro, dkk., 2005:34), adalah:

"Recollection, a spiritual exercise designed to render God's presence troughtout one's being. The method employed (rhytmical repetitive invocation of God's name) to attain this spiritual concentration"

Maksudnya adalah ingatan atau suatu latihan spiritual yang bertujuan untuk menyatakan kehadiran Tuhan seraya membayangkan wujud-Nya atau suatu metode yang dipergunakan untuk mencapai konsentrasi spiritual (dengan menyebut nama Tuhan secara ritmis dan berulang-ulang).

Selain membaca kitab suci al Quran, yang menjadi khas dari aktifitas ini adalah majelis dzikir itu sendiri, yakni duduk bersama-sama, kemudian masing-masing berdzikir dengan pelan. Lafaz dzikir yang dibaca adalah Tahmid (ucapan Alhamdulillaah), Takbir (Allaahuakbar), Tasbih (Subhaanallaah), Tahlil (Laa ilaaha illallaah), dan istighfar (Astaghfirullaah). Di dalam majelis dzikir itu juga terdapat majelis ilmu, dan inilah majelis dzikir yang paling afdhol (Taufik, 2005). Berkumpul mengingat Allah dengan dipandu oleh seorang panutan seraya disampaikan tentang ilmu-ilmu yang berkenaan dengan apa yang dibaca dan dipahami dari aktifitas dzikir.

Dalam pembahasan mengenai ayat al Quran yang berbunyi: "ingatlah aku (Allah) niscaya Aku ingat kepada kamu." Mustafa Zaid berkata (Shalaby, 2001:224), "saya percaya, pembaca tidak akan menganggap apa yang disebut dzikir itu adalah gerakan akrobatik yang dibuat-buat dan dilakukan dengan cekatan oleh sebagian orang yang mengaku bertasawuf, juga dengan jeritan yang keras. Namun, sebenarnya maksud dzikir itu ialah agar orang mukmin senantiasa berhubungan dengan Allah melalui ibadah, sekalipun dalam keadaan ramai. Dzikir ini menyebabkan seorang mukmin merasa malu kepada Tuhannya, serta 
tidak lalai untuk ingat kepada-Nya dan melaksanakan dengan sempurna apa yang diwajibkan kepadanya. Di dalam keadaan begini, seluruh hatinya diselubungi oleh rasa khusyu' kepada Allah dan mematuhi serta merasa malu kepada-Nya”.

Dalam diri manusia (Rojabi, 2006:140), terdapat kecenderungan luhur yang disebut dengan keecenderungan beribadah. Dengan dasar ini, manusia memahami dirinya sebagai entitas yang bergantung (dependen) dan berhasrat mendekatkan diri pada hakikat yang disucikan dan dimuliakannya. Manusia menyampaikan ketidakberdayaannya kepada Tuhan, seraya melaksanakan tugas-tugas ibadahnya sebagai hamba, baik mahdloh (langsung) maupun ghoiru mahdloh (tidak langsung).

Langsung, dapat berupa dzikir dan menyelamkan dirinya pada lafadz yang dibaca selama dalam majelis dzikir. Tidak langsung dapat berupa berkumpulnya mereka dengan orang lain yang memiliki kesamaan tujuan untuk mencari penyembuhan kekeringan spitualitas. Dari majelis itu di antara mereka dapat terjalin persatuan umat dan meningkatkan silaturrahim. Karena media ini bisa mempertemukan pihak-pihak yang biasanya sulit untuk bertemu, serta menjadikan mereka semakin akrab.

Sebagai produk massa yang terus menerus dipraktekkan dan semakin hari menjadi populer di kalangan masyarakat, majelis dzikir kehilangan subtansinya. Sebagaimana sifat produk massa itu sendiri yakni bersifat sementara. Karena massa ditandai oleh komposisi yang selalu berubah dan berada dalam batas wilayah yang selalu berubah pula (Bungis, 2007:98). Nilai-nilai ibadah di atas yang akan diraih oleh pelaku dzikir akan menjadi kabur ketika penggunaan atau melakukan aktifitas dzikir ini sampai pada titik jenuh.

Seiring proses tersebut, di dalam majelis dzikir bukan hanya diisi oleh orang yang mencari penyembuhan rohani tapi orang-orang dengan berbagai kepentingan dan tujuan masuk di dalamnya. Termasuk kepentingan non ibadah yang bersifat ekonomis-politis.

Hampir tidak ada sisi kehidupan sekarang ini yang luput dari cengkeraman budaya massa. Sentuhan tangannya adalah Midas, yang sanggup menyulap segala sesuatu yang disentuhnya menjadi emas. Budaya massa juga telah mengaburkan 
batas antara dakwah dan hiburan, antara belajar agama dan bertamasya, antara yang sakral dan yang profan, juga antara sadar spiritual dan praktek budaya massa. Budaya massa adalah momen konsumsi yang oleh Dominic Strinati dalam An Introduction to Theories of Popular Culture (2009), digambarkan sebagai budaya populer yang dihasilkan melalui teknik-teknik industrial produksi massa dan dipasarkan untuk mendapatkan keuntungan sebanyak-banyaknya dari khalayak konsumen massa.

Keberadaan budaya massa terkait erat dengan komodifikasi di segala bidang kehidupan yaitu suatu proses pengubahan segala objek sehingga menjadi punya nilai tukar (Piliang, 2003:88). Produk budaya, dilihat dari mass culture, tidak memproduksi komoditi bagi pengguna (user) namun lebih ditujukan bagi konsumen (consumer). Terdapat perbedaan pokok antara keduanya. Pengguna adalah mereka yang memang menggunakan suatu objek, dalam hal ini adalah dzikir untuk memenuhi kebutuhan hakiki mereka dan kerapkali kebutuhan yang bersifat ibadah maupun sosial. Konsumen berbeda karena lebih mengedepankan konsumsi pribadi yang bersifat materi terbatas dan sementara.

Begitu juga pada majelis dzikir, mereka para pengguna (baca: pelaku) dzikir bisa saja terjebak pada praktek konsumsi bukan lagi menggunakannya dan menghayati akan apa yang dilakuinya. Bahkan, di luar pelaku dzikir ini sebagian orang berorientasi mencari keuntungan dengan memanfaatkan mobilisasi massa, meski dalam majelis dzikir sekalipun. Majelis dzikir dapat dikatakan sebagai media yang dikatakan oleh McQuail (Bungis, 2007:85), bahwa media mampu mengontrol serta mengarahkan pikiran publik atau massa. Dengan media majelis dzikir dapat dikeruk profitnya melalui berbagai strategi yang menyerupai dengan hal-hal yang mendukung aktifitas dzikir. Padahal bukan bagian dari tujuan utama dzikir, hanya kostum dan embel-embel kegiatan yang disematkan pada majelis dzikir.

Setiap terdapat mejelis dzikir manusia berbondong-bondong datang dengan mengenakan seragam putih-putih, ada pula berjaket hitam, serta atribut bendera kebesaran nama majelis dzikir yang memimpin mereka dalam berdzikir. Budaya massa yang diciptakan darinya adalah pengenaan kostum yang bila 
dikaitkan dengan aktifitas pembacaan dzikir belum tentu sepenuhnya mendukung pada kekhusyuan ibadah mengingat dan menyebut nama Allah SWT sebagai tujuan utama dzikir. Memang dalam agama ada anjuran pakaian tertentu yang baik dikenakan dalam beribadah. Namun, hal itu juga mampu ditangkap oleh sebagian orang sebagai lahan untuk mencari profit ekonomis.

Lebih jeli lagi majelis dzikir dengan tersedianya massa yang secara otomatis datang dengan segala niat baiknya, dapat dimanfaatkan untuk kepentingan politis. Massa merupakan masyarakat sosial yang dapat pula berinteraksi dalam aspek keagamaan, hukum, ekonomi, pendidikan maupun politik (Soekanto, 1999:369). Sekali lagi majelis dzikir dapat dimanfaatkan sebagai media. Saat-saat pemilihan misalnya, seperti yang disebut oleh Nur Sholihin (2003) dalam tulisannya "Politik: NU dan Tradisi Istigotsah", bahwa mulai dari Pilkades, Pilwali, Pilkada sampai Pilpres, gelaran istighotsah menjadi ramai dihadiri oleh kontestan-kontestan pemilu. Mereka hadir di sana adalah untuk mecari simpatik massa. Mereka mempunyai kepentingan politik yang dengannya diharapkan mendulang dukungan.

Tujuan akhir dari majelis dzikir adalah pengingatan pada hakikat Allah Yang Maha Besar, atau pengingatan kepada sumber dari segala perwujudan dan segala sifat-sifat. Menurut Shalaby (Shalaby, 2001:224) dalam mengomentari ayat yang tercantum dalam QS. Al-Anfal:2, bahwa Tuhan menganggap orang-orang yang mengingat-Nya, baik lelaki atau perempuan, sebagai golongan yang menerima ampunan dan pahala yang besar. Dzikir tidak diakui sama sekali, bilamana dilakukan dengan bisnis dan jeritan yang tidak menimbulkan rasa takut dan khusyu' serta ngeri di dalam diri orang-orang yang berdzikir itu. Padahal, sifat-sifat inilah yang harus menghiasi suasana dzikir tersebut.

Sementara ketika mejelis dzikir diapahami dari sudut pandang budaya massa, sebuah produk budaya dengan bungkus agama, namun telah kehilangan subtansinya. Sebagian pelaku dzikir tidak memahami keutamaan dari dzikir beserta majelisnya, hanya mereka terbuai dalam seremoni ritual mulai awal hingga akhir di tengah masyarakat jika tidak ingin mengatakan kerumunan (crowd) orang-orang yang melakukan hal yang sama, serta aspek ekonomi dan 
politik memiliki peran mengontrol pasar dengan menganggap pelaku dzikir adalah konsumen.

\section{Penutup}

Bisa jadi, itulah sebagian dari fenomena budaya massa yang disadari atau tidak, telah mengalir dalam sekat-sekat dan sendi-sendi keseharian hidup masyarakat. Budaya massa masuk dalam relung ibadah dakwah semacam majelis dzikir. Budaya massa menggeser kebudayaan tinggi dalam sebuah aspek dzikir yakni beribadah mengingat kepada Allah dengan aktifitas imitasi oleh pelaku yang tidak sepenuhnya paham dengan tujuan dari dzikir, yang terjadi adalah massa jamak tidak dapat menemukan subtansi dari perkumpulan tersebut. Dalam prosesnya, di antara mereka akan merasakan sebuah gejala alienasi. Keterasingan meski terdapat dalam lingkaran yang awalnya memberikan penyembuhan dan pencerahan jiwa.

Majelis dzikir yang sarat akan nilai ibadah, kemudian beralih menjadi ajang eksploitasi ekonomis dengan segala kulit yang menyelubunginya. Majelis dzikir juga tidak dapat menghindar dari incaran para pencari dukungan atau orang-orang yang bergerak di bidang politik. Majelis dzikir merupakan produk budaya masyarakat yang rentan dikaburkan antara nilai spiritual di dalamnya dengan pasar ekonomi-politik terhadapnya.

Untuk itu, perlu upaya menjelaskan spiritrualisasi majelis dzikir agar tidak terjebak pada praktek budaya massa. Majelis dzikir adalah media penyempurnaan moral masyarakat yang sama halnya dengan memahami esensi agama Islam itu sendiri. 


\section{DAFTAR PUSTAKA}

Afif, Afthonul. 2007. Ustad Muda dan Industri Budaya Massa. (http://afifiderridean.blogspot.com, diakses 13 Juli 2011).

Ahira, Anne. 2007. Manfaat Majelis Dzikir. (http://AnneAhira.com, diakses 13 Juli 2011).

Bungis, Burhan, M. 2007. Sosiologi Komunikasi: Teori, Paradigma, dan Diskursus Teknologi Komunikasi di Masyarakat. Jakarta: Kencana.

Djoko Damono, Sapardi. 2004. Kebudayaan Massa dalam Kebudayaan

Indonesia: Sebuah Catatan Kecil dalam Ecstasy Gaya Hidup:

Kebudayaan Pop dalam Masyarakat Komoditas Indonesia. Yogyakarta: Mizan.

Ibrahim, Subandi, Idi. 2005. Lifestyle Ecstasy: Kebudayaan Pop dalam Masyarakat Komoditas Indonesia. Yogyakarta: Jalasutra.

Ibrahim, Subandi, Idi. 2004. Ecstasy Gaya Hidup: Kebudayaan Pop dalam Masyarakat Komoditas Indonesia. Yogyakarta: Jalasutra.

Jumantoro, Totok \& Amin, Munir, Samsul. 2005. Kamus Ilmu Tasawuf. Jakarta: Amzah.

Kuntowijoyo. 2004. Budaya Elite dan Budaya Massa dalam Ecstasy Gaya Hidup: Kebudayaan Pop dalam Masyarakat Komoditas Indonesia. Yogyakarta: Mizan

Patters, Reiza. 2010. Budaya Massa/Mass Culture. Kompasiana.

Piliang, Yasraf Amir. 2003. Hipersemiotika: Tafsir Cultural Studies Atas Matinya Makna, Yogyakarta dan Bandung: Jalasutra.

Rojabi, Mahmoud. 2006. Horison Manusia. Jakarta: Al-Huda.

Shalaby, Ahmad. 2001. Kehidupan Sosial dalam Pemikiran Islam. Jakarta: Amzah.

Sholihin, Nur . 8 Maret, 2003. Politik: NU dan Tradisi Istigotsah. Kompas.

Soekanto, Soerjono. 1999. Sosiologi: Suatu Pengantar. Jakarta: RajaGrafindo 
Persada.

Strinati, Dominic. 2007. Popular Culture: Pengantar Menuju Teori Budaya Populer, alih bahasa: Abdul Mukhid, Yogyakarta: Jejak.

Taufik. 2005. Fenomena Dzikir Sebagai Eskapisme Spiritual Masyarakat Modern. SUHUF. Jurnal Fakultas Agama Islam Universitas Muhammadiyah Surakarta. Volume ke-17, Nomor 2: 131-146.

Yudha, Formen, Ali. 2004. Gagap Spiritual: Dilema Eksistensial di Tengah Kecamuk Sosial. Yogyakarta: Kutub. 